\title{
Uma adolescente em situação de sofrimento emocional: a busca espontânea por ajuda em um serviço de saúde mental
}

\author{
A teenager in a situation of emotional suffering: the spontaneous search for help in a mental health \\ service
}

Un adolescente en situación de sufrimiento emocional: la búsqueda espontánea de ayuda en un servicio de salud mental

Recebido: 30/07/2021 | Revisado: 07/08/2021 | Aceito: 11/08/2021 | Publicado: 15/08/2021

\author{
Cristiano Furtado Scarpazza \\ ORCID: https://orcid.org/0000-0001-8285-1658 \\ Universidade Luterana do Brasil, Brasil \\ E-mail: cristianoscarpazza@gmail.com \\ André Guirland Vieira \\ ORCID: https://orcid.org/0000-0002-4487-6480 \\ Universidade Luterana do Brasil, Brasil \\ E-mail: andre.vieira@ulbra.br \\ Honor de Almeida Neto \\ ORCID: https://orcid.org/0000-0002-5245-9441 \\ Universidade Luterana do Brasil, Brasil \\ E-mail: honor.neto@ulbra.br
}

\begin{abstract}
Resumo
Este estudo objetiva apresentar o caso de adolescente vulnerável social e familiarmente que procurou espontaneamente um serviço de saúde mental. Este estudo de caso com adolescente de 15 anos, partiu de três entrevistas em diferentes momentos. $\mathrm{Na}$ primeira, entrevista aberta, com roteiro de perguntas semiestruturadas. Na segunda, foi construído um álbum fotográfico da família e vivências para pontuar momentos e lembranças da jovem. Na terceira, foi aplicada a técnica linha da vida, que consiste em uma linha da vida da participante, marcando pontos positivos e negativos de sua trajetória. A adolescente de 15 anos cursa o nono ano do Ensino Fundamental e no primeiro encontro referiu ser lésbica. Procurou o Serviço de Saúde Mental de Município do interior do Mato Grosso em julho de 2020. Com pais separados, viveu em cada etapa da vida com avó ou mãe. Sua mãe sumiu durante cinco meses e mora com uma namorada fora do estado. A adolescente teve fatos traumáticos em sua vida: desordem familiar, violência intrafamiliar, falta de apoio e falta de referência familiar, abuso sexual, automutilação, tentativo de suicídio. Percebe-se, com este estudo, que a estrutura familiar é muito importante na vida dos jovens, pois a falta de apoio prejudica seu desenvolvimento e crescimento saudáveis. A família da jovem não possibilitou seu pleno desenvolvimento e agiu como fator de risco para seu sofrimento emocional, pois não propiciou um bom desenvolvimento biopsicossocial, nem suporte e apoio profissional qualificado que pudessem ajudá-la a compreender as suas necessidades e a enfrentar seus problemas.
\end{abstract}

Palavras-chave: Adolescência; Sofrimento emocional; Apoio social; Saúde mental.

\begin{abstract}
This study aims to present the case of a socially and familiarly vulnerable adolescent who spontaneously attended a mental health service. This case study with a 15-year-old teenager was based on three interviews at different appointments. At the first time, it was performed an open interview, with a script of semi-structured questions. In the second one, a photographic album of her family and her experiences was built to punctuate the young woman's moments and memories. In the third appointment, the lifeline technique was applied. It consisted of a participant's lifeline, marking the positive and negative points of her trajectory. The 15-year-old teenager is actually in the ninth year of elementary school and at the first meeting she reported being lesbian. She attended the Municipal Mental Health Service in a rural city at the state of Mato Grosso, Brazil, in July 2020. With parents divorced, she has randomly lived with her grandmother or mother along each stage of her life. Her mother then left home five months ago and lives in another brazillian state with her girlfriend. The adolescent had traumatic events in her life: family disorder, domestic violence, lack of support, absent family reference, sexual abuse, self-mutilation, and even attempted suicide. This study shows that family structure is very important in the lives of young people, as the lack of support impairs their healthy development and growth. The young woman's family did not allow her full development and acted as a risk factor for her emotional suffering, as it did not provide a good biopsychosocial development, or qualified professional support that could help her in understanding her needs and faceing the problems.
\end{abstract}

Keyword Adolescence; Emotional distress; Social support; Mental health. 


\section{Resumen}

Este estudio tiene como objetivo presentar el caso de un adolescente social y familiarmente vulnerable que buscó espontáneamente un servicio de salud mental. Este estudio de caso con un adolescente de 15 años se basó en tres entrevistas en diferentes momentos. En la primera entrevista abierta, con guión de preguntas semiestructuradas. En el segundo, se construyó un álbum fotográfico de la familia y vivencias para resaltar momentos y recuerdos de la joven. En el tercero se aplicó la técnica de la línea de vida, que consiste en la línea de vida de una participante, marcando los puntos positivos y negativos de su trayectoria. La adolescente de 15 años cursa noveno año de primaria y en la primera reunión informó que es lesbiana. Acudió al Servicio de Salud Mental de un municipio del interior de Mato Grosso en julio de 2020. Con los padres separados, vivió en todas las etapas de su vida con una abuela o una madre. Su madre lleva cinco meses desaparecida y vive con una novia fuera del estado. La adolescente tuvo hechos traumáticos en su vida: desorden familiar, violencia intrafamiliar, falta de apoyo y falta de referencia familiar, abuso sexual, automutilación, intento de suicidio. Este estudio muestra que la estructura familiar es muy importante en la vida de los jóvenes, ya que la falta de apoyo perjudica su sano desarrollo y crecimiento. La familia de la joven no permitió su pleno desarrollo y actuó como factor de riesgo para su sufrimiento emocional, ya que no le brindó un buen desarrollo biopsicosocial, ni apoyo y apoyo profesional calificado que pudiera ayudarla a comprender sus necesidades y enfrentar sus problemas.

Palabras clave: Adolescencia; Angustia emocional; Apoyo social; Salud Mental.

\section{Introdução}

A adolescência tem sido compreendida como uma fase muito suscetível ao sofrimento emocional. Neste período, o diagnóstico de depressão é entendido como um sofrimento emocional grave e esta doença têm sido cada vez mais prevalentes (Crivelatti, Durman \& Hofstatter, 2006). O processo de adolescer é complexo e exige de todos especial atenção a este jovem, pois é a fase na qual o indivíduo se constrói e que passa por grande desenvolvimento físico e emocional, no qual vai adquirindo sua autonomia. Além disso, passa por profundas mudanças físicas e psicossociais que irão influenciar diretamente na personalidade e nas suas relações sociais (Pasini et al., 2020).

Há vários fatores de risco para o agravamento dos problemas em saúde mental, como doenças psiquiátricas, violência conjugal e abuso de drogas pelos pais. Estas questões podem influenciar o risco dos adolescentes desenvolverem transtornos mentais, assim como quando expostos a outras situações, como alterações sociais e angústias psicológicas associadas a desastres naturais, conflitos armados e crises humanitárias (Pinto et al., 2014).

É possível evidenciar a prevalência de comportamento autolesivo dos adolescentes, que são estigmatizados pelos pais, pelos professores e profissionais de saúde. Estes adolescentes, ao invés de sofrerem preconceito, deveriam ser ajudados por essas pessoas. As pessoas confundem os comportamentos e acreditam que os jovens estão se comportando desta forma para chamarem atenção e conseguirem o que desejam. Estas atitudes elevam o nível de tensão dos adolescentes e prejudicam a procura por ajuda profissional (Aquino, 2020). Macedo et al. (2011) pontuam que ainda há uma predominância de busca por ajuda profissional pelos adolescentes que vem por problemas relacionados à afetividade e esses precisam ser acolhidos pelas equipes de saúde.

O suicídio tem sido apontado como a segunda causa de morte entre jovens de 15 a 29 anos, entretanto, apesar das taxas diferirem segundo cada país são os países mais pobres que elevam essas taxas. Entre os fatores de risco individual, aparecem os transtornos mentais, o alto consumo de álcool e drogas, perdas econômicas, antecedentes familiares, dentre outros (OPAS, 2016). Isto coloca os adolescentes em situação bastante vulnerável para ideação suicida ou a tentativa ou prática do mesmo. Paralelo a isso, as ações de saúde mental destinadas aos jovens ainda são muito incipientes e quando existem são marcadas pela institucionalização e correm o risco de atrelar o diagnóstico a problemas psiquiátricos e não observam o entorno social e familiar no qual o jovem está inserido (Vicentin \& Gramkow, 2010).

Muitos conflitos existentes na adolescência podem ter início na infância e na sua trajetória de vida, pois eles geralmente não são resolvidos como deveriam. As causas do sofrimento emocional são complexas e podem ser motivadas pelos mais diversos fatores presentes em cada etapa do desenvolvimento humano (Soares, 2020). Sendo assim, quanto mais 
precoce é realizado o acompanhamento e tratamento desta criança ou jovem, mais chances eles têm deste evento ser passageiro.

Alguns adolescentes acreditam que o sofrimento emocional seja algo individualizado, e possuem dificuldades para compartilhar as emoções e sentimentos, acreditando que podem superar as adversidades sozinhos. Enfrentam as crises de forma individualizada, tratando-as como uma questão essencialmente interna, como algo que criaram. Sendo assim, acreditam que devem superar este momento sozinhos, chegando a se culpabilizarem pelo ocorrido (Rossi et al., 2019).

Com um mundo contemporâneo cada vez mais exigente, o adolescente possui a missão de ingressar na vida adulta, sendo exposto a relações de competição que não oferecem refúgio para lidar com o sofrimento. Vivemos em uma sociedade individualista, com empobrecimento das redes de pertencimento, que exige cada vez mais habilidades emocionais e cognitivas para lidar com um universo de relações. Este mundo nos desafia a lidar com uma vida possível entre as negociações do desejo e da realidade (Prieto, 2017).

O funcionamento insatisfatório da família pode repercutir de maneira significativa na saúde mental do adolescente. Quando não há o suporte adequado pela família frente às necessidades para seu desenvolvimento saudável, podem surgir doenças relacionadas ao sofrimento emocional, como sintomas depressivos ou depressão (Baptista, Baptista \& Dias, 2001).

O período da adolescência pode ser composto por características distintas, que estão diretamente ligadas à construção do autoconceito e da autoestima. Neste período, os jovens passam a ter responsabilidades sociais, familiares e profissionais, sendo considerada uma fase de grande aprendizagem de normas, conceitos sociais e morais. Em algumas situações são compreendidos e em outras seus direitos são violados (Pasini et al., 2020).

Este período é peculiar em decorrência das várias transformações e exigências que ocorrem nesta fase, sendo caracterizada por estressores do processo de desenvolvimento desencadeados nesta etapa. Sendo assim, as mudanças físicas e psicológicas, durante a formação de sua identidade afetam significativamente seu comportamento (Avanci, Assis \& Oliveira, 2008). Diante das dificuldades enfrentadas nesta fase, os jovens se deparam com sentimentos de muita angústia (Novaes, 2018). Passam a querer menos contato com a família e a se relacionar com seus pares (Oliveira, 2016), pois não querem mais seguir regras e aumentando o sentimento de serem incompreendidos pelos pais (Rodrigues, 2018). Entretanto, menos querendo ficar longe, a família é um suporte social insubstituível ao adolescente (Baptista et al., 2001).

O adolescente busca apropriar-se de seu papel social, construindo sua identidade. Procura maior aceitação em grupos sociais, mesmo que isso exija novas condutas. É comum nesta fase o início da experimentação do novo, podendo fazer uso de drogas e iniciar a vida sexual. Neste período, podem surgir dificuldades que gerarão angústias e sentimentos diversos. Sendo assim, a família é fundamental para a consolidação da identidade alcançada, encorajando o adolescente a enfrentar seus desafios e reforçando nele o comportamento adequado (Senna \& Dessen, 2012).

A relação dos pais e cuidadores com os filhos é essencial para que o seu desenvolvimento seja saudável. As relações sociais iniciais estabelecidas são importantes e devem ser mantidas durante o processo de crescimento. Elas influenciarão o desenvolvimento humano, de forma interdependente aos aspectos orgânicos e biológicos. É importante ainda que a qualidade dessas relações seja saudável, caso contrário, pode prejudicar o desenvolvimento de habilidades e capacidades, emocionais, sociais e adaptativas do sujeito. Observando tal afirmação, é importante atentar para as questões de relação parental na adolescência e considerar este período como um momento intenso de descobertas e de consolidação de identidade (Magnani \& Staudt, 2018). Fatores como o cuidado e o suporte familiar diminuem a probabilidade de os adolescentes apresentarem problemas psicológicos, sendo assim, esses fatores promovem o desenvolvimento positivo do jovem (Ehnvall, Hadzi-Pavlovic \& Malhi, 2008).

Mângia et al. (2003) salientam que as necessidades dos adolescentes em situação de sofrimento psíquico vão além de sua queixa inicial, mesmo que não apresentem um diagnóstico bem definido, é necessário que o profissional de saúde mental 
desenvolva novos olhares e uma escuta qualificada, buscando o planejamento e o desenvolvimento de ações de promoção da saúde mental, oferecendo ao indivíduo um atendimento individualizado e qualificado.

Em função de esta temática ser de extrema relevância social, o objetivo deste estudo foi apresentar o caso de uma adolescente de grande vulnerabilidade social e familiar que procurou espontaneamente um serviço de saúde mental, apresentando hipótese diagnóstica de depressão, associada a vários fatores negativos dentro de sua trajetória de vida, como bullying, desordem familiar, violência sexual, violência familiar, autolesão e tentativa de suicídio.

\section{Metodologia}

Esta pesquisa baseia-se em um estudo de caso de adolescente em acompanhamento em serviço de saúde mental. Esta metodologia é utilizada como a primeira abordagem de um tema, ou seja, observa-se um ou poucos indivíduos sobre um tema ainda não muito explorado (Pereira, 2000). Esta é uma estratégia de investigação qualitativa que irá abordar características e problemáticas específicas de um ou de poucos casos. Ele permite estudar o caso no seu contexto e pode utilizar-se de várias fontes de dados e parte de um problema de pesquisa que questiona sobre o porquê ou o como algo acontece (Meirinhos \& Osório, 2016). Este tipo de investigação conta a história de um fenômeno passado ou atual ou a história de uma pessoa em relação a determinado assunto, realizando-se por observação direta ou entrevistas sistematizadas, realizadas em um ou mais momentos. Também é possível utilizar outras fontes de dados que auxiliem no alcance dos objetivos do estudo, ou seja, é um estudo no qual se faz um mergulho no que está sendo investigado para entendê-lo em profundidade (Martins, 2008).

A escolha por esta estratégia metodológica ocorreu em função de que nosso objetivo é descrever o caso da forma mais detalhada possível segundo o objetivo desta pesquisa. Segundo Pereira; Shitsuka; Parreira \& Shitsuka (2018), este tipo de estudo pode trazer informações ricas e contribuir com o avanço do conhecimento. Para tanto, deve possuir características especiais, observando-se como o evento aconteceu e quais variáveis o determinaram. O caso escolhido é especial porquê é de uma adolescente que procurou espontaneamente o serviço de saúde mental por sentir necessidade de um apoio psicológico. Isto é raro acontecer, em especial com este grupo populacional.

Neste estudo, o questionamento realizado foi sobre o porquê de a adolescente ter procurado o Serviço de Saúde Mental do município. Para tanto, este caso foi escolhido em função de estar em acompanhamento há alguns meses por um psicólogo, e entrevistada em três diferentes momentos. As entrevistas foram conduzidas de forma que a cada encontro o pesquisador utilizasse técnicas distintas. No primeiro encontro, para conduzi-lo foi realizada uma entrevista semiestruturada, especialmente construída para este fim, no qual teve um roteiro de perguntas pré-elaboradas. No segundo, foi construído um álbum fotográfico da família e vivências, de forma a que fossem pontuados momentos e lembranças da jovem. No terceiro, foi aplicada a técnica linha da vida, que consiste em uma linha representando a vida da participante, marcando pontos positivos e negativos de sua trajetória de vida. O início da linha é representando pelo nascimento e o final o momento atual.

Após os três encontros, o pesquisador ainda retornou mais uma vez para esclarecer alguns fatos. A história será relata a seguir, procurando-se utilizar a cronologia dos fatos e, em alguns momentos, trazer as próprias falas da adolescente.

Este estudo seguiu todos os protocolos presentes na Resolução 510/2016, garantindo o anonimato da adolescente e tendo sua autorização para a realização da entrevista. O nome da adolescente utilizado no presente trabalho é fictício (Margarida), visando proteger sua identidade. O estudo foi cadastrado na Plataforma Brasil e aprovado sob o número 4.566.279 no Comitê de Ética e Pesquisa da Universidade Luterana do Brasil. 


\section{Resultados}

\section{Relato do caso}

Margarida, 15 anos, se identifica como lésbica e cursa o nono ano do Ensino Fundamental. Procurou atendimento no Serviço de Saúde Mental de um Município do interior do Estado do Mato Grasso, em julho de 2020. Tem cinco irmãos: Sabrina, Eduardo, Roberta, Antônio e Fernando (sendo o último filho do pai com a atual esposa) e foi criada até os cinco anos pelos pais, que até este momento viviam em união estável. Durante este período, presenciou o pai alcoolizado agredindo a mãe. Entretanto, relata não lembrar muito disso, mas diz que o ambiente era muito pesado, pois o pai bebia muito e batia muito na sua mãe. Refere que sua trajetória de vida foi complicada, pois sua infância foi uma época muito conturbada.

Morava com a avó paterna desde que nasceu. Nesta época, moravam juntos ela, a avó, o pai, a mãe e os irmãos. Seus pais se divorciaram quando ela tinha aproximadamente cinco anos, então ficou morando com a avó, a mãe e os irmãos. Foi assim até os 12 anos. Depois disso, morou um ano com a mãe no Estado do Rio Grande do Sul e, atualmente, mora somente com a avó e a irmã caçula Roberta.

Até os cinco anos, refere que convivia muito pouco com seu pai, pois ele era muito ausente. Assim, este não sabe como ela cresceu e pensa que nunca teve um pai em sua vida. Mesmo morando na mesma casa, praticamente não convivia com ele e ficava mais com a mãe e a avó.

Sobre as lembranças da creche, relatou que era muito sapeca. Ao falar sobre isso, fica muito constrangida e diz "eu pegava geral". Ao ser questionada sobre o que isto significava, ela refere que ficava na casinha de bonecas com meninos e meninas, "eu me lembro de ter ficado com um monte de gente nesta casinha, principalmente com a minha melhor amiga. Hoje ela namora". Refere que era muito pequena e não sabia muito bem o que era aquilo, mas "pegava as meninas e meninos". Refere ter sofrido bulliyng desde os quatro anos de idade.

Aos seis ou sete anos, se mudou de bairro e de escola. Foi na época de sua formatura no Jardim de Infância, na qual os pais não a levaram. Neste momento, já estavam separados. Para ela, este evento foi ruim, pois ela gostaria de ter se formado no Jardim de Infância junto com seus amigos e amigas.

Aos oito anos relata ter sofrido abuso sexual que, segundo ela, "foi a pior coisa que aconteceu na minha vida". Nesta época, sofria bullying na escola, pois falava coisas sem noção e fazia "xixi nas calças diariamente". Em relação às lembranças boas, comenta que brincava muito com os amigos e que "pegava" suas amigas dentro do banheiro da escola. Conta que quando foi abusada (aos oito anos), estava brincando junto com seus irmãos no "Buracão", ainda no bairro em que foi criada. Aí um menino baixou suas calças e "penetrou lá dentro por cinco minutos. Eu só senti o gosto de sangue na minha boa e saí correndo”. Ele também a levou para a casa dela para assistirem juntos vídeos pornográficos.

A adolescente comentou lembrar-se de pouca coisa sobre seu passado. Entretanto, comenta sobre a festa de seu aniversário de nove anos: estava com seus irmãos Eduardo e Roberta. Sua mãe comprou os salgadinhos e seu pai ajudou a arrumar a festa, mesmo já estando separados nesta época. Conta que a única foto que tem de sua mãe é com sua irmã e avó, mas porque a mãe fez uma montagem. Nesta época estudava na Escola Municipal Nossa Senhora Aparecida. Diz que tinha vários amigos na escola, mas aos poucos foi se afastando deles.

Lembra somente de fatos isolados de sua vida ou das coisas que sua avó vai lhe contando. Fala que não se lembra de seus 10 anos (apesar de ter 15 anos no momento da entrevista), diz que sua memória é muito ruim. Conta que sofria bullying na escola e, neste período, continuava a fazer "xixi” nas calças. Quando morava com a mãe e a avó paterna, durante sua infância, sua mãe era cozinheira do Clube, às vezes, ia para lá com ela. Ela gostava de estar lá. O clube era da Igreja, mas ela não se sente mais confortável neste lugar. 
Relatou que era a pior aluna da aula, não fazia as tarefas de casa e brigava com todo mundo na aula e "tinha 14 assinaturas na caderneta". Diz que fazia muitas coisas ruins, brigava com todo mundo e "pegava" geral. Em relação à família, refere que o relacionamento era bom, pois vivia com sua mãe, avó paterna e irmãos.

Quando fala da mãe se entristece e diz que não a tem mais junto. Ela sumiu durante cinco meses e quando souberam notícias dela, estava no Rio Grande do Sul. Tinha ido atrás de uma mulher que conheceu pela Internet. Passado um tempo, a mãe veio buscar ela e a irmã e foram morar no Sul.

Neste período em que morou no Sul do Brasil (por volta dos 12 anos de idade), fez aulas de circo por um tempo e tinha crises de depressão, mas só ficou sabendo que era depressão meses depois. Na época, sua mãe a levou para a psicóloga, passou por psicoterapia dos 08 aos 12 anos. Ela achou um papel na bolsa da mãe em que a psicóloga explicava que ela tinha depressão. Refere que não sabia lidar com isso, que é muito difícil, e que ainda hoje está aprendendo a lidar com a doença. Nesta época, a melhor lembrança que tem é de seu aniversário, pois ficou menstruada um dia após. Ficou muito feliz com isto, pois foi o dia em que ficou "mocinha". As amigas já tinham menstruado e ela ficava triste por ainda não ter tido esta experiência.

Morou até os 12 anos com a avó paterna e refere que o relacionamento era bom. Não teve contato com o pai durante seu crescimento e desenvolvimento, pois quando ele saiu de casa não viu mais os filhos. Atualmente este contato retornou.

Sobre o avô não fala com ele há muito tempo e refere terem perdido o contato também, pois ele se divorciou da avó e foi morar em outra cidade, mas diz que sente falta dele. Diz que se lembra de coisas boas com ele, pois ele lhe trazia bolo e mais um monte de coisas. Era carinhoso com ela e sente falta disso.

Aos 13 anos, refere ter as piores lembranças de sua vida. Já morava no Sul. Não teve festa de aniversário, que mãe fez festa de aniversário somente para sua irmã. Se sente culpada por a mãe gostar mais da irmã do que dela. Acredita que a mãe gostava mais da namorada do que dela e dos irmãos. Fala que sofreu tentativa de estupro nesta época, de um primo da namorada de sua mãe.

A adolescente relatou que enquanto morava no Sul do país, tentou se cortar no banheiro da escola com uma lâmpada, que não conseguiu por alguém da escola interviu por ela, que já estava se automutilando há algum tempo. Disse que as boas lembranças dessa época eram quando tomava sorvete e enquanto fazia aulas de circo no Projeto ABEFI (Projeto Ação Encontro de apoio à comunidade).

Refere que ainda no Sul foi um período muito complicado de sua vida, que a mãe saia com a namorada dela saíam para fazer uso de bebida alcoólica e ela e os irmãos ficavam sozinhos, que não possuíam o que comer e que muitas vezes ela e os irmãos tinham que pegar comida no lixo para ser alimentarem. Relatou que ela e os irmãos viviam fora de casa até altas horas da noite, pois a mãe não queria os filhos dentro de casa.

Em função de que a situação no Sul, com a mãe, ficou muito ruim, pediram para que ela a levasse de volta à avó paterna. Fala que quando o irmão Eduardo nasceu, viveu até os sete anos em outra cidade, lá ele foi estuprado e acabou desencadeando problemas psicológicos muito sérios. Faz uso de medicamentos e está sendo dopado.

Comentou que acredita que sempre teve depressão, mas que não tinha crises, que após morar no Sul começou a se cortar, que suas amigas também lhe ajudavam a se cortar, que vivia mal e chorando pelos cantos, que a mãe acredita que era drama para chamar a atenção, e que pensa dessa forma até hoje. Apontou que chorava a noite e tinha crises, que não queria ver a mãe, que se sentia abandonada por ela e que se sente assim até hoje. Se sente abandonada pelo pai e pela mãe até hoje. Isto a faz se sentir muito mal.

Voltou para a sua cidade, no norte do país, em 2020 e resolveu procurar acompanhamento psicológico. Não pediu ajuda para sua família, pois refere sentir-se constrangida. Mas a avó paterna acha bom ela estar fazendo acompanhamento psicológico. Atualmente usa Fluoxetina e mais dois remédios que não lembra o nome. A mãe segue morando no Rio Grande do 
Sul, e ela possui pouco contato com esta. Refere não querer morar com a mãe nunca mais, pois ela já sumiu vários meses e negligenciou ela e os irmãos. Entretanto, apesar de uma trajetória que ela classifica como conturbada, não associa a depressão à sua história de vida.

Aponta que o irmão mais velho, Eduardo, mora com a mãe até hoje. A irmã mais velha, com 17 anos, atualmente mora com a avó materna, a caçula Roberta mora com a avó paterna e ela. Fala sentir falta do irmão Antônio e tem medo dele a esquecer. Diz que a avó não gosta quando ela se comunica com ele. Entretanto, este contato é somente por telefone. Parece aqui que ela acaba idealizando esta relação.

Refere que contou para a avó que é lésbica, que se sente bem com a avó, mas aponta que ela é homofóbica e isto atrapalha sua relação. Ela é da igreja e o homossexualismo é esquisito para ela, acredita que isto não é coisa de Deus. Mas refere querer muito que a avó a apoie. Diz que ficou aliviada quando resolveu se assumir como lésbica, pois sofria emocionalmente por isso, ficava chorosa e triste, tinha medo da família não aceitar. Relatou que não gosta que lhe toquem, muito menos a avó, pois tem uma sensação ruim.

Deseja morar com o pai, mas acha que sua avó iria ficar triste. O pai, quando morava junto com eles, era alcoolista, mas segundo seu relato, ele parou de beber. Diz que a avó a deixaria morar com o pai e que gostaria de morar um tempo com ele para ver se seria bom, pois nunca morou com ele depois que os pais se separaram.

Analisando fotografias para compreender melhor sua trajetória de vida, afirmou não se lembrar de quando era criança, mas ao ver uma foto dela com o pai em sua infância relatou que acredita que era muito feliz, pois quando olha para a foto, tem uma sensação boa. Sente saudades do pai, fala com ele às vezes e justifica não ter mais frequência porque ele trabalha muito. Seu relato sobre o pai é bastante contraditório, pois ao mesmo tempo em que fala que tinha pouca relação com ele, que ele era alcoolista e agredia a mãe, diz que suas lembranças alegres eram com ele e fala querer ir para São Paulo morar com o pai.

Falou sobre a avó, com quem mora atualmente. Levou para o encontro fotos dela com a avó de quando era bebê e de quando tinha em torno de dois anos e refere que a maioria das fotos que tem é dela com a avó. Diz que quando olha essas fotos, tem um misto de tristeza e felicidade e um pouco de angústia, apontando que a avó sempre esteve presente em sua vida. Refere que acredita que na infância era feliz, mas não tem nenhuma memória deste tempo, somente o que sente olhando as fotos.

Refere que quem the ajudou a escolher as fotos para levar ao encontro foi a avó, assim, ela vai falando um pouco de cada foto escolhida. Com isso, a adolescente vai construindo a sua história. Conta que as lembranças que tem de quando estava na creche eram de que ela era uma criança sorridente. Atualmente não sorri muito, tem um olhar triste.

Lembra pouco da irmã caçula quando era bebê, mas refere que cuidava dela. Ela foi para o sul também e voltaram juntas. Relata que brigam muito e que ela não gosta muito de carinho, mas aponta que ela também não gosta muito de receber carinho, prefere oferecer.

O irmão por parte de pai (Fernando) mora com o pai e a mãe dele em São Paulo e refere ter bastante contato com ele por aplicativo de mensagens. Novamente comenta que sente muita falta do pai. Ao longo das entrevistas, pareceu que ela tem uma idealização muito grande do pai, pois se refere a ele o tempo todo. Sendo uma situação curiosa, pois, comentou que seu contato com ele foi muito pequeno.

Sobre o momento atual, comenta não estar acontecendo nada de bom, mas muitas coisas ruins. Está com problemas de adaptação, diz que não consegue mais se equilibrar, conforme aparece em sua fala a seguir.

Eu tento, mas não consigo mais me equilibrar, está muito difícil para mim. Respiro fundo, penso em coisas positivas, tento me acalmar, mas eu não consigo. Eu simplesmente, eu não consigo me controlar e isso tá muito difícil pra mim. Eu tento, eu falei, eu tento, eu tomo os meus remédios todos os dias. Só que tá difícil. 
Falou que teve três crises recentes, sendo que em duas delas foi parar no hospital. Disse que ainda vem se cortando, que se sente aliviada e bem quando se corta, como se saísse um peso de suas costas, mas que se sente fraca por estar assim.

Aponta não receber apoio da família. A irmã não ajuda, pois faz bullying com ela também, fala que ela cheira mal, mesmo após ela tomar banho, diz que é feia e gorda, bate em sua cabeça. A avó não a apoia em nada, segundo ela, mas a ajuda no tratamento. Atualmente tem pouco contato com sua mãe e com seu pai, mas refere que é esquisito. Deseja ir morar com o pai, mas tem dúvidas se isso será bom. Fala em querer cursar Medicina, acha que este desejo vem de uma série que assistiu. Achou mágico operar as pessoas e salvar vidas.

Tem medo de que sua família não aceite sua sexualidade, só contou para a sua avó, mãe e pai. Este aceitou muito bem e diz que está feliz por ela, mas a avó é preconceituosa e não aceita. Sua madrasta também aceitou. Quer estar formada em medicina aos 25 anos, fazendo residência no Canadá. Entretanto, tem medo de fracassar na medicina, não conseguir fazer. Aos 35 anos se vê trabalhando em um hospital, morando nos Estados Unidos da América e ganhando bem, longe de sua família e casada ou namorando. Quer com 35 anos estar estável financeiramente, com sua mulher, casa e suas coisas e ter, pelo menos, um filho, que poderá ser adotado. Para ela, fracassar seria não conseguir se sair bem no trabalho, ser uma péssima esposa e mãe.

Relatou que procurou o serviço de saúde mental pelo fato de ter apresentado crises de humor. Estas crises foram bem fortes a ponto de ser necessária sua hospitalização. Contou que recebeu pouco apoio familiar e que isso fez com que ela tomasse a iniciativa de busca por apoio profissional. Disse que está em sofrimento psíquico e com dificuldades em enxergar outras possíveis saídas para sua vida. Assim, acredita que o atendimento psicológico possa auxiliá-la.

Acredita-se que sua procura ao Serviço de Saúde Mental não ocorreu somente em função da depressão, que seu sofrimento psíquico vai além de sua hipótese diagnóstica.

\section{Discussão do caso}

O caso acima apresentado mostra a história de vida de uma adolescente com a família bastante desorganizada. Durante seus 15 anos de vida a jovem morou com os pais, com a avó paterna, com a mãe, com a mãe e sua namorada, e com a avó novamente. Atualmente, idealiza morar com pai e diz ter muito desejo disto, mas ao mesmo tempo, muito medo.

Costa (2014) salienta que o sofrimento é uma condição democrática, no qual todos os seres humanos são afetados, sendo a intensidade deste sofrimento diferente, assim como as vivências individuais, que serão responsáveis por modular esta intensidade. Para o autor, o sofrimento psíquico está presente na angústia da busca pelo sentido da vida e pela busca da felicidade.

Em estudo realizado em 2020, com histórias de vida de adolescentes, foi apontado por esses jovens sensações de desespero, confusão mental, angústia, sentimento de inferioridade, baixa autoestima, medo, descontrole, comportamentos impulsivos e pensamentos suicidas (Rossi; Marcolino; Speranza \& Cid, 2019). Esses sinais também foram observados na adolescente deste estudo de caso, gerados, possivelmente pela pouca estrutura e apoio familiar que teve ao longo de sua vida.

Em sua infância, a adolescente conviveu com um pai alcoolista que agredia na mãe. Embora este fato seja marcante na vida de qualquer pessoa, ela relata lembrar-se de pouca coisa de sua história. Relacionamentos violentos repercutem no indivíduo como desvalor e abandono, o que causa sofrimento psíquico (Rossi; Marcolino; Speranza \& Cid, 2019). A adolescência é, possivelmente, a fase da vida em que o sujeito mais precisa de um ambiente protetor que lhe ofereça condições adequadas de desenvolvimento e crescimento. Para isso, é preciso uma rotina segura e tranquila, pois somente assim, conseguirá passar por esta fase turbulenta sem grandes danos emocionais. Atualmente, no mundo, aproximadamente $20 \%$ dos adolescentes apresentam problemas disfuncionais de origem mental, como depressão, pensamentos suicidas e isolamento 
social (Pigozi \& Machado, 2015). Este percentual é muito grande se levarmos em conta suas consequências. A adolescente estudada ficou com uma referência familiar muito difusa e sem saber muito bem com quem podia contar. Assim, desde os oito anos apresenta episódios de depressão, que vem sendo tratada somente com medicação, apesar de ela relatar que teve um período na infância que a encaminharam para acompanhamento psicológico.

A adolescência, assim como qualquer outro momento da vida, é um período suscetível ao surgimento de sintomas e instalação de quadros de transtornos mentais, sendo marcado por constantes transformações psíquicas e de conflitos internos. Porém, a intensidade e o histórico deste sofrimento estão ligadas à atmosfera em que vive esses jovens, como suas características individuais e de seu meio social (Barata; Nóbrega; Jesus; Lima \& Facundes, 2015).

No período da adolescência, as relações sociais estão se estabelecendo e o jovem vai tendo mais autonomia e liberdade para poder se relacionar. Ele enfrenta desafios o tempo todo. $\mathrm{Na}$ escola, ele convive com outros adolescentes que vivenciam outros problemas. Este ambiente é de muita aprendizagem, mas também de muita dor e sofrimento. Alguns não conseguem manter relações saudáveis e são alvo de violência e bullying. Esses geralmente possuem poucos amigos e têm a autoestima afetada, pois são criticados pelos adultos, pais e professores. Os pais reforçam as críticas e perdem a oportunidade de ajudar o filho, afastando-o e não ganhando sua confiança. Assim, o adolescente ainda pode acreditar ser merecedor do bullying sofrido. Essas situações agravam ainda mais sua baixa autoestima (Neto, 2005).

Uma das características mais comuns em adolescentes depressivos é a baixa autoestima. Esta, geralmente, vem acompanhada pelo mau desempenho escolar, por problemas comportamentais, pelo abuso de álcool e outras drogas e por ideação suicida (Bahls, 2002). Na escola, observa-se que as relações de violência se perpetuam. Os jovens são agressores, vítimas, ajudantes, defensores, reforçadores ou neutros e estas situações sempre envolvem questões de domínio e submissão (Elias, 2011). No Brasil, violência e bullying são temas que permeiam o cotidiano do território escolar e a vida em sociedade. Este tema faz parte da mídia, dos discursos políticos e de políticas públicas, pois seu impacto é avassalador na vida das pessoas (Schilling, 2014).

A violência cometida dentro do ambiente escolar tem suas raízes na desestrutura familiar, na pobreza, na discriminação, na falta de infraestrutura e na falta de vínculo no meio em que os jovens convivem. Isso traz repercussões no rendimento escolar, frustração e agressividade (Ataide, 2000). Esta violência é uma forma de exclusão social e de dominação de uns contra outros e ocorre por meio de abusos no relacionamento interpessoal (Giordani; Seffner \& Dell'aglio, 2017).

Observa-se no caso apresentado que a jovem entrevistada, ao mesmo tempo em que se identifica como vítima de bullying e de violências das mais diversas formas, também é agressora, pois em seu relato, desde pequena, "pegava meninos e meninas no banheiro", criava confusão na escola e com seus colegas. Assim, é importante que se reflita sobre esta temática, já que seu efeito na vida desses jovens os coloca em situação de muita vulnerabilidade. Ora são agressores ora vítimas, mas o que fica evidente é que como a fase da adolescência é um período em que os jovens querem se afirmar ao mesmo tempo em que serem aceitos, ficam oscilando ente uma ponta e a outra da violência.

Desde a infância, a adolescente entrevistada relata situação de abuso sexual. Revelou que aos oito anos teve sua primeira situação, na qual um menino abusou sexualmente dela. Mais tarde, perto dos 12 anos teve outra situação de abuso sexual.

A violência sexual é caracterizada por atos praticados de natureza sexual e são lesivos ao corpo e à mente da pessoa que é violada (Brasil, 1990). Ela pode ter duas especificidades: exploração sexual e abuso sexual. A primeira caracteriza-se pela relação mercantil estabelecida com o corpo; a segunda é qualquer ação de interesse sexual cometida por um ou mais 
adultos em relação a uma criança ou adolescente. Esta pode ocorrer no âmbito intrafamiliar, com pessoas com quem tenham relações afetivas; ou extrafamiliar, com outros que não tenham situação de parentesco (Florentino, 2015).

Este tipo de violência pode desencadear várias sequelas, tanto como físicas como emocionais, podendo ser a curto e longo prazo. Além disso, pode haver uma repetição deste fenômeno ao longo da vida. Há um consenso psicanalítico que afirma que o fato traumático pode ser reproduzido nos relacionamentos que serão estabelecidos, mesmo que superficialmente, com características de isolamento e indisponibilidade para relacionamentos sociais ou amorosos. Isto pode desencadear violências intrassubjetivas, intersubjetivas e transubjetivas. Assim, as intervenções com esses grupos devem ser pautadas na interdisciplinaridade, devendo haver boa comunicação e a criação de vínculo entre os profissionais, os serviços disponíveis e as pessoas ou grupos atendidos para o sucesso do atendimento (Boroati, 2009).

Estudos têm apontado várias consequências que o abuso sexual traz para crianças e adolescentes, deixando marcas profundas físicas, psicológicas, emocionais, sexuais, dentre outras. Isto pode comprometer a vida da vítima, não somente sexualmente, mas especialmente, na saúde emocional (Prado, 2004; Romaro \& Capitão, 2007; Cunha, Silva \& Giovanetti, 2008). Quando a pessoa passa por uma situação dessas, não somente seus direitos são violados, como são despertadas novas sensações que os jovens ainda não sabem como lidar (Prado, 2004). Entre 2011 e 2018, foi registrado no Brasil, no ano de 201720.331 denúncias de abuso sexual contra crianças e adolescentes, caindo um pouco em 2018 para 17.093(Bezerra \& Piana, 2019). Apesar desta pequena queda este número continua alto, ainda mais se considerarmos que o percentual de denúncias é muito menor do que os abusos cometidos. A visibilidade deste problema passou a ocorrer a partir da criação do Estatuto da Criança e do Adolescente (ECA), entretanto ainda são poucas as denúncias se verificarmos a dimensão e complexidade do problema, pois o abuso sexual acarreta muitas consequências às suas vítimas e várias estão associadas à sua vida sexual na idade adulta (Carvalho, 2020).

Os graus de severidade dos efeitos sobre o sujeito e as consequências do abuso variam de acordo com a idade, o início da violência, a duração e a quantidade de vezes, o grau de violência e a diferença de idade entre a vítima e o agressor. Além disso, também influenciam o fato de existir vínculo entre os dois e se teve ameaças na relação (Furniss, 1993). As consequências do abuso sexual, praticado contra crianças e adolescentes, são graves, pois violam a vítima física e emocionalmente e organicamente esta sai da situação, muitas vezes, com lesões físicas gerais, nos órgãos genitais, com hematomas, contusões e fraturas (Florentino, 2015).

Na maior parte das vezes, este tipo de violência não é denunciada e a vítima acaba ficando mais vulnerável a outras agressões e violências. A família, por sua vez, omite o fato e faz de conta que este não existiu, o que aumenta o dano sobre a vítima, já que está se sente abandonada afetivamente (Romaro \& Capitão, 2007). A adolescente não relata em sua história se contou ou não para sua família sobre o abuso, mas é bem provável que sequer ela tivesse tido coragem de contar, pois lhe faltou alguma referência familiar mais próxima em quem poderia confiar, pois em sua infância e adolescência foi vivendo cada momento com uma parte desta família. Ao longo de sua história, do nascimento até o momento atual, não teve uma referência familiar que lhe ajudasse a se organizar.

A família é um importante fator na rede de apoio dos adolescentes, já que as figuras familiares exercem grande influência na construção dos vínculos afetivos, como autoestima, autoconceito e construindo modelos de relações que serão utilizados em outros momentos e contextos de interação social (Volling \& Elins, 1998). É a instituição na qual os indivíduos iniciam os processos de desenvolvimento e se desenvolvem padrões de comportamentos, valores morais, sociais, éticos, espirituais, entre outros. Assim, a família auxilia na formação da personalidade e contribui para a consolidação do caráter, noções de ética e solidariedade (Macedo \& Monteiro, 2006), sendo o principal alicerce que os sujeitos têm no início de sua vida já que com apoio emocional (Picanço, 2012) é possível o jovem crescer com mais segurança, autonomia e responsabilidade. Os laços afetivos construídos dentro da família auxiliam no desenvolvimento do sujeito, o que possibilita que 
desenvolvam relações sociais mais saudáveis (Dessen \& Polonia, 2007), pois ela é a base para se aprender convivência e socialização (Camilo et al., 2018).

Segundo Pratta e Santos (2006), a literatura ressalta que a qualidade do tempo disponível por parte dos pais é que vai determinar como o adolescente vai enfrentar e vivenciar as inseguranças desta fase, fortalecendo as relações estabelecidas entre pais e filhos durante o tempo em que estiverem juntos. Assim, é importante a presença dos pais no dia-a-dia do adolescente, para que se sintam importantes e que desenvolvam uma identidade familiar de superação dos problemas com o grupo.

A família é fonte de segurança e referencial para a vida dos adolescentes, pois este se encontra em pleno processo de formação de sua identidade, sendo fundamental nesta fase apoio e orientação familiar de forma a transmitir-lhes valores, normas e modelos de conduta (Romanelli, 2003). O Estatuto da Criança e Adolescente (ECA) refere que é dever da família o direito à vida, à saúde, à alimentação, à educação, ao lazer, à profissionalização, à cultura, à dignidade, ao respeito, à liberdade e a convivência familiar e comunitária. Além disso, aponta que esta deve proteger as crianças e adolescentes de forma a colocá-los a salvo de toda forma de negligência, discriminação, exploração, violência, crueldade e opressão (Brasil, 1990).

Quando crianças e adolescentes estão expostos à negligência familiar, sofrem todos os tipos de violência, como se observa na história de vida da adolescente entrevistada. Aparentemente, ela não se dá conta de que sua vida é permeada por essas situações: alcoolismo do pai; a mãe de era espancada pelo pai ao longo dos anos que viveram juntos; o abuso sexual aos oito anos de idade; a dificuldade com a referência de seu local de moradia já que a cada momento vivia com um familiar diferente; sumiço da mãe por cinco meses; mudança para o sul do país para morar com a mãe e a namorada; separação dos irmãos, com cada um vivendo em lugares diferentes; novo abuso quando morava no Sul, época em que ela e os irmãos tinham que passar na rua, pois a mãe e a namorada não os queriam dentro de casa, dentre outros. Todas as situações de violência vividas pela adolescente trouxeram como consequência sua depressão; esquecimento ou "falta de memória", como ela própria retrata; automutilação; tentativa de suicídio. Em nenhum momento aponta preocupação da família ou sequer conhecimento desta sobre essas questões.

Casos de autolesão e suicídio entre os adolescentes têm aumentado nos últimos anos, sendo atualmente considerados os principais problemas de saúde pública no Brasil e no mundo (Hawton, Saunders \& O'Connor, 2012). A Organização Mundial de Saúde (OMS) classifica a autolesão no contexto da violência autoinfligida como equivalente ao uso intencional de força física ou ameaça contra si próprio (Organização Mundial de Saúde, 2016). Ela é considerada como qualquer comportamento intencional que envolva agressão direta ao próprio corpo. É considerada sem intenção consciente de suicídio, mas como forma de aliviar as tensões (Cardoso, 2011).

A automutilação, autolesão ou self cutting não são consideradas como tentativa clara de suicídio, muito menos uma vaidade. Devem ser entendidas como uma busca por tentativas de lidar com as emoções negativas. Perante os conflitos internos e externos, o indivíduo responde com um comportamento autolesivo que lhe dá a sensação de alívio imediato da tensão, como se a dor emocional (indefinida e não localizável) fosse direcionada a dor física. E esta é menos dolorosa e com contornos mais definidos do que a dor psicológica ou emocional (Leong, Wu \& Poon, 2014).

A adolescente entrevistada por este estudo relata sentir prazer e alívio quando passa a se cortar e a se autolesionar. Ela também comenta sobre uma tentativa de suicídio, realizada dentro da escola na qual estudava, o que vem ao encontro de estudo que aponta que tentativas de suicídio, suicídio, autoflagelação, autopunição e autolesão são tipos de violência autoinfligida (Brasil, 2016).

Os comportamentos autolesivos são considerados problema de saúde pública e tem aumentado o número de casos em adolescentes e nas escolas. Esta é uma forma disfuncional desses grupos enfrentarem os problemas da vida cotidiana, pois muitos possuem poucas estratégias de enfrentamento de situações adversas. Este comportamento pode se tornar incapacitante se vier a persistir na vida adulta (Almeida, 2015). 
Ao se automutilizar ou autolesionar, o sujeito aprecia a dor física e esta lhe desvia a atenção da dor emocional e psicológica, que muitas vezes é insuportável. Entretanto, os conflitos que este sujeito não enfrenta, são apenas momentaneamente afastados, eles continuam a existir dentro dele e trazem consequências graves para a sua vida (Dinamarco, 2011).

Essas agressões físicas que o sujeito faz com seu corpo é precedida pelo aumento de tensão, raiva de si próprio, depressão, disforia, sensação de perda de controle como consequência de sensação de rejeição ou abandono, culpa, vazio existencial, sentimento de inutilidade (Giusti, 2013). Estas questões nos remetem novamente ao relato da adolescente que aponta depressão, abandono pela mãe e pelo pai, culpa, sentimento de inutilidade. Ela relata em algumas partes de sua história que não teve pai, talvez por isso, a idealização com ele. Por outro lado, a irmã mais nova, que ela conta que ajudou a cuidar, comete "bullying" com ela, chamando-a de feia, suja e fedorenta.

Garreto (2015) aponta que ambientes inseguros ou inconsistentes levam o sujeito a um desenvolvimento interpessoal pobre. Além disso, pessoas que cresceram nesses ambientes têm poucas habilidades para lidar com suas emoções. Guisti (2013) aponta fatores de risco para esses comportamentos, dividindo-as em características pessoais; transtornos psiquiátricos; problemas relacionados à infância; problemas sociais e familiares.

Em relação às características pessoais, salienta falta de mecanismos de adaptação; pessimismo; insegurança; distorção da imagem corporal; baixa autoestima; instabilidade emocional; impulsividade; autodepreciação. Sobre os transtornos psiquiátricos, coloca transtorno de personalidade Borderline; ansiedade; depressão; transtornos alimentares; transtornos de uso de substâncias; outros transtornos da personalidade. Em relação aos problemas de infância, aponta negligência; abuso sexual, físico e emocional; dificuldade de apego; doença grave ou cirurgias na infância; estresse emocional precoce. Sobre as questões sociais, salienta o "Bullying"; informações sobre automutilação pela mídia; colegas que se automutilam. Por fim, sobre as dificuldades de relacionamento familiar, estão: dependência de álcool; separação precoce dos pais; desvalorização por parte da família; violência familiar; relação familiar disfuncional; depressão em algum dos pais. Como observamos nos relatos da adolescente, vários desses fatores fazem parte de sua história em cada uma dessas características.

Comportamentos de risco podem ser evitados e mediados pelo apoio social (Alves \& Dell'aglio, 2015). O apoio familiar, dos educadores, de profissionais de saúde e de grupos integrados em projetos sociais e educativos, caracteriza uma rede de apoio. Esta propicia a saúde dos adolescentes, oportunizando a superação dos desafios decorrentes das mudanças físicas, mentais e sociais. Desta forma, contribuem para seu desenvolvimento pessoal e social e para a construção de sua autonomia, possibilitando que escolham caminhos mais saudáveis de vida (Costa, Zeitoune, Queiroz, Garcia \& Garcia, 2015).

É importante ainda frisar que a adolescente recorreu ao serviço especializado em saúde mental em primeiro lugar, mesmo havendo outras possíveis redes primárias de apoio como família e amigos. Isto não é comum, pois muitos adolescentes possuem dificuldades em buscar o tratamento adequado perante seu sofrimento emocional, pois associam esta busca de ajuda a fatores à relacionados à loucura, como se o simples fato de procurar esse apoio profissional confirmasse o diagnóstico (Carvalho, Costa \& Bucher-Maluschke, 2007).

Costa et al. (2015) salientam que os adolescentes oferecem em seus discursos significados associados ao núcleo familiar, como rede de apoio informal para o cuidado à saúde. Isto confirma as construções sócio-históricas do sistema de referência formado por interações primárias, sendo fundamental à construção para os cuidados à saúde.

Apesar do movimento da reforma psiquiátrica iniciado há várias décadas, existe ainda muita desinformação sobre a busca e o alcance dos jovens em sofrimento emocional à terapêutica adequada. Há muito pouca participação e suporte familiar, o que proporciona sofrimento ao adolescente (Monteiro et al., 2012).

A busca pelo apoio profissional ocorre pelo sofrimento psíquico, muitas vezes, sem hipótese diagnóstica, tendo o profissional que lidar com a identificação da necessidade dos adolescentes. Ele deve olhar além do próprio diagnóstico, pois o 
jovem tem necessidade de ser ouvido e de ser visto. Assim, o profissional em saúde mental tem o dever de compreender o que pode estar contido na queixa principal e identificar as necessidades de saúde e os cuidados que serão desenvolvidos. As necessidades apresentadas na queixa inicial pela família ou pelo jovem são limitadas e encobrem questões mais complexas e individuais, e o olhar profissional deve contemplar todas essas necessidades dos adolescentes, contribuindo para a prevenção da instalação dos transtornos psíquicos ou para sua atenuação (Mângia et al., 2003).

A trajetória de vida dos adolescentes para a vida adulta certamente será marcada por períodos de crises e sofrimentos, sendo o sucesso ou o fracasso pessoal subordinados ao suporte recebido. Sendo assim, a atenção em saúde mental para os adolescentes, compreende a identificação das necessidades e as promoções intersetoriais capazes de criar políticas de saúde mental mais eficazes a esta população (Mângia et al., 2003).

$\mathrm{O}$ adolescente em sofrimento emocional apresenta uma pluralidade de queixas que vão além da queixa inicial, a depressão vem acompanhada de suas várias facetas abarcadas por ela, considerando a visão psicoafetiva, comportamental, psicossocial e físico-orgânico. Assim, a depressão tem várias etiologias na categoria das "causas" da doença, sendo necessário o profissional precisa compreender essa necessidade do paciente (Ribeiro, Medeiros, Coutinho \& Carolino, 2012).

$\mathrm{O}$ adolescente compreende a escuta qualificada como algo que considera as suas necessidades individuais nos momentos de crises. Esta é tida como apoio significativo e organizador, pois facilita os relatos acerca dos sentimentos e angústias experimentados nos momentos mais críticos e abre espaço para a ressignificação da crise, bem como para a criação conjunta de um projeto de cuidado a ser inserido dali em diante. Sendo assim, o profissional com seu olhar integral sobre seu paciente, oferece a ele um olhar acolhedor, o que o valoriza como sujeito e facilita o estabelecimento de um vínculo de confiança (Rossi et al., 2019).

Dalgalarrondo (2000) salienta que o diagnóstico psicopatológico ajuda a compreender o sofrimento psíquico do paciente, que ajuda a direcionar o tratamento mais indicado. Entretanto, se deve considerar as peculiaridades existente entre os indivíduos, sendo assim, o diagnóstico pode ser restritivo em relação à compreensão da totalidade humana. Bezerra (2014) afirma que o diagnóstico passou a se definir em uma consulta a partir de uma lista de critérios de inclusão e exclusão, o que isso fez com que os números de diagnósticos aumentassem e o olhar amplo ao indivíduo fosse reduzido.

Serpa Jr., Campos, Pitta, Diaz \& Dahl, (2014) propõem a necessidade de novo olhar na forma de tratamento, que envolve a integração das vivências pessoais e a realização dos anseios individuais nos diferentes âmbitos da vida. Este olhar não deve se basear somente no diagnóstico na saúde mental considerando a doença como um processo. Afirmam ainda que diante do diagnóstico há a dificuldade para a implantação de uma nova forma de tratamento, que em relação ao transtorno mental se baseia nos aspectos comportamentais. Entretanto, esta forma não leva em considerações as manifestações subjetivas do indivíduo que exigem maior observação clínica, dificultando assim o plano terapêutico e uma melhor compreensão do processo de adoecimento.

\section{Considerações Finais}

Cumprindo com o objetivo de analisar a trajetória de vida do adolescente ao buscar atendimento em serviço de saúde mental, este artigo reafirma a importância de se observar a adolescência como um período complexo de vida, no qual o jovem necessita de apoio para vivenciar esta fase da forma mais saudável possível. Este é um momento no qual há uma crise existencial, normal da adolescência, caracterizada por sofrimento emocional intenso causado por diversos fatores intrafamiliares e extrafamiliares. Na jovem investigada, esta crise se intensificou em função da sequência de fatos traumáticos que ocorrem ao longo de seus quinze anos e da total falta de estrutura familiar para a auxiliar a vivenciar este momento. 
A adolescente vivenciou desordem familiar, violência intrafamiliar, consumo excessivo de álcool, falta de apoio e falta de referência familiar, abuso sexual, automutilação, tentativo de suicídio. Estas questões acabaram por trazer como consequência a depressão, doença muito comum e que afeta negativamente a forma como a pessoa se sente, age e pensa. Ela provoca sentimento de tristeza e perda de interesses em atividades que, geralmente, causariam prazer e alegria.

A família da jovem acabou sendo um fator de risco para o sofrimento emocional. Ela não teve um ambiente propício ao seu bom desenvolvimento biopsicossocial, nem suporte e apoio profissional qualificado, que pudesse compreender as suas necessidades e lhe oferecer um tratamento adequado. Estranhamente a jovem buscou, por sua conta e risco, auxílio em serviço de saúde mental. Com isso, ela criou para ela a oportunidade de ser atendida e auxiliada.

A família tem papel importante na vida das crianças e adolescentes. Ela é essencial durante todo o processo de crescimento e desenvolvimento humano. Assim, acredita-se que são importantes programas educativos de orientações aos pais e cuidadores, de forma a oferecer-lhes a oportunidade de reflexão sobre este momento do ciclo de vida bem como lhes fornece ferramentas para poderem lidar de forma mais adequada com seus filhos. Assim, a família pode atuar como suporte emocional deste grupo e não fragilizados a ponto de se automutilarem ou tentarem suicídio frente às dificuldades vivenciadas no cotidiano. Quando a família não faz o papel dela de apoio ao adolescente, este fica muito desamparado. É muito difícil que procure auxílio por conta própria, como fez a adolescente investigada. Pensamos que ela é uma exceção, e que devemos valorizar sua atitude. Entretanto, também sabemos que para cada jovem que procura muito ficam sofrendo sozinho, se automutilando ou cometendo suicídio.

Os resultados deste estudo apontam para a necessidade de novas investigações para compreender o motivo pelo qual os jovens procuram atendimento de saúde mental por conta própria, pois neste relato de caso, a jovem pouco falou sobre isso, mesmo sendo estimulada com várias perguntas. Conhecendo melhor sobre os adolescentes com sofrimento emocional, os serviços de saúde podem planejar ações que atinjam esses jovens e possam promover sua saúde, oferecendo elementos importantes para a compreensão das perspectivas dos adolescentes, e subsidiando intervenções promotoras da saúde, valorizando as práticas de cuidado em relação à saúde mental dos adolescentes.

Pode-se concluir que há a necessidade de os adolescentes serem reconhecidos como indivíduos suscetíveis ao sofrimento psíquico, e que os atendimentos especializados valorizem e reconheçam as necessidades deste público, reconhecendo suas vozes e compreendendo-os como possuidores do direito de participarem da construção das ações coletivas que visem ao seu próprio cuidado.

Este trabalho nos mostra a importância da realização de estudos futuros sobre o sofrimento psíquico dos adolescentes, pois esta temática ainda tem muito a ser descoberta. Sabe-se que os jovens vivem questões complexas na adolescência e que muitos não têm o apoio familiar e social de que necessitam. Entretanto, como é difícil ver o jovem dentro dos serviços de saúde, é necessário que se pesquise mais sobre quem são os jovens em sofrimento emocional, quem são suas famílias e o que o Sistema de Saúde e a escola podem oferecer para auxiliá-los, já que esta é a fase que marca seu crescimento e desenvolvimento. Além disso, é importante que se possa realizar diagnósticos locais de forma a conhecer a especificidade de cada comunidade de jovem e verificar suas dificuldades e necessidades. Estes estudos poderão embasar políticas públicas de defesa da criança e do adolescente e auxiliar os serviços a desenvolverem ações que possam impactar positivamente na vida desses jovens.

\section{Referências}

Almeida. R. S. (2018). A prática da automutilação na adolescência: o olhar da psicologia escolar/ educacional. Ciências Humanas e Sociais. Alagoas, 4 (3), p. $147-160$.

Alves, C. F. \& Dell'aglio, D. D. (2015). Apoio Social e Comportamentos de Risco na Adolescência. Psico, v. 46, n. 2, p. $165-175$. 
Avanci, J. Q., Assis, S. G. E.; Oliveira, P. \& Raquel V. C. (2008). Sintomas depressivos na adolescência: estudo sobre fatores psicossociais em amostra de escolares de um município do Rio de Janeiro, Brasil. Cadernos de Saúde Pública [online]. 24 (10) p. 2334-2346. <https://doi.org/10.1590/S0102311X2008001000014>.

Aquino, J. C. M. de. (2020) Autolesão não suicida na adolescência: aspectos a serem abordados na Atenção Básica. Portal PEBMED. Disponível em: https://pebmed.com.br/autolesao-nao-suicida-na-adolescencia-aspectos-aserem-abordados-na-atencao-basica/.

Ataide, Y. D. B. (2000) A Educação e a cultura da paz. Revista da FAEEBA. Salvador, 16 (14), p. 21-28, jul/dez..

Bahls, Saint-Clair. (2002) Aspectos clínicos da depressão em crianças e adolescentes: clinical features. Jornal de Pediatria [online]. v. 78, n. 5 <https://doi.org/10.1590/S0021-75572002000500004>.

Baptista, M. N.; Baptista, A. S. Daher, D. \& Righetto, R. (2001). Estrutura e suporte familiar como fatores de risco na depressão de adolescentes. Psicologia: Ciência e Profissão [online]. v. 21, n. 2 <https://doi.org/10.1590/S1414-98932001000200007>.

Barata, M. F. O.; Nóbrega, K. B. G. da; Jesus, K. C. S. de; Lima, M. L. L. T. de; Facundes, V. L. D. (2015), Rede de cuidado a crianças e adolescentes em sofrimento psíquico: ações de promoção à saúde. Revista de Terapia Ocupacional da Universidade de São Paulo, [S. l.], v. 26, n. 2, p. 225-233. https://www.revistas.usp.br/rto/article/view/90134.

Bezerra Jr., B.. A psiquiatria contemporânea e seus desafios. (2014). In: Bezerra Jr., B.; COSTA, Jurandir Freire; Zorzanelli, R.(orgs.). A criação de diagnósticos na psiquiatria contemporânea. Rio de Janeiro: Garamont.

Bezerra, M. S.\& Piana, M. C. (2019). 18 de maio é todo dia: a violência sexual contra criança e adolescente no Brasil. In: Congresso Brasileiro de Assistentes Sociais 2019. http://broseguini.bonino.com.br/ojs/index.php/CBAS/article/view/1255.

Brasil. (1990). Presidência da República. Casa Civil. Subchefia para Assuntos Jurídicos. Lei no 8.069, de 13 de julho de 1990. Dispõe sobre o Estatuto da Criança e do Adolescente e dá outras providências.

Brasil. (2016) Ministério da Saúde. Secretaria de Vigilância em Saúde. Departamento de Vigilância de Doenças e Agravos Não Transmissíveis e Promoção da Saúde. Viva: instrutivo notificação de violência interpessoal e autoprovocada [recurso eletrônico]. Ministério da Saúde, Secretaria de Vigilância em Saúde, Departamento de Vigilância de Doenças e Agravos Não Transmissíveis e Promoção da Saúde. 2. ed. Brasília : Ministério da Saúde.

Camilo, A. S.; Roza, A. R.; Silva, J. P.; Goedert. A. L.; Favreto, A.; Brandão, F. L. F. \& Demarco, T. R. C. (2018). A Importância da Relação Família-Escola no Desenvolvimento Educacional Infantil. In.: Baumer, C.M. (org). Repositório de artigos do curso de psicologia: práticas em psicologia. Pato Branco

Cardoso, C. P. S. (2011). Adolescência na voz de adolescentes: bem estar e comportamentos autodestrutivos, um estudo exploratórioDissertação (Mestrado em Psicologia). Faculdade de Psicologia. Universidade de Lisboa, Lisboa, 2011. Disponível em: <repositorio.ul.pt/handle>.

Carvalho, I. S., Costa, I. \& Bucher-maluschke , J. (2007). Psicose e Sociedade: interseções necessárias para acompreensão da crise. Rev. Mal-Estar Subj., Fortaleza, 7 (1), p. 163-189. http://pepsic.bvsalud.org/scielo.php?script=sci_arttext\&pid=S1518-61482007000100010\&lng=pt\&nrm=iso>

Carvalho, A. O. (2020). Abuso sexual infantil e as consequências no âmbito sexual das vítimas. Centro Universitário UNIFAAT. Curso de Psicologia. Trabalho de Conclusão do Curso de Psicologia. Atibaia: São Paulo.

Costa, I. I. (2014). Sofrimento humano, crise psíquica e cuidado: dimensões do sofrimento e do cuidado humano na contemporaneidade. In: COSTA, Ileno Izídio da (Org), Sofrimento humano e sofrimento psíquico: da condição humana às “dores psíquicas”. Brasília: Editora Universidade de Brasília, p. $23-67$.

Costa, R. F.; Zeitoune, R. C. G.; Queiroz, M. V. O.; Garcia, C. I. G. \& Garcia. M. J. R. (2015). Redes de apoyo al adolescente en el marco del cuidado sanitario: interfaz entre salud, familia y educación. Rev. Esc. Enferm. USP 49 (05). https://doi.org/10.1590/S0080-623420150000500005.

Crivelatti, M. M. B.; Durman, S.\& Hofstatter, L. M. (2006). Sofrimento psíquico na adolescência. Texto \& Contexto Enfermagem, vol. 15, n. especial.

Cunha, E. P., Silva, E. M. \& Giovanetti, A. C. (2008). Enfrentamento à violência sexual infanto-juvenil: expansão do PAIR em Minas Gerais. Belo Horizonte: UFMG.

Dalgalarrondo, P. (2000). Psicopatologia e semiologia dos transtornos mentais. Porto Alegre: Artmed.

Dessen, M. A.\& Polonia A. da C. (2007). A Família e a Escola como contextos de desenvolvimento humano. Paidéia: Ribeirão Preto v. 17, n. 36, p. 21 - 41.

Dinamarco, A. V. (2011). Análise exploratória sobre o sintoma de automutilação praticada com objetos cortantes e/ou perfurantes, através de relatos expostos na internet por um grupo brasileiro que se define como praticante de automutilação. 2011. 117f. Dissertação (Mestrado em Psicologia) - Instituto de Psicologia, Universidade de São Paulo, São Paulo, 2011. <www.teses.usp.br/teses/disponiveis/dinamarco.pdf>.

Elias, M. A. (2011). Violência Escolar. Caminhos Para Compreender e Enfrentar o Problema. Educação em Ação.São Paulo: Ática Educadores.

Ehnvall A; Parker G, Hadzi-Pavlovic D. \& Malhi G. (2008). Perception of rejecting and neglectful parenting in childhood relates to lifetime suicide attempts for females--but not for males. Acta Psychiatr Scand. Jan;117(1):50-6. doi: 10.1111/j.1600-0447.2007.01124.x. Epub 2007 Nov 19. PMID: 18028251.

Florentino, B. R. B. (2015). As possíveis consequências do abuso sexual praticado contra crianças e adolescentes. Fractal: Revista de Psicologia, 27 (2), p. 139-144. doi: http://dx.doi.org/10.1590/1984-0292/805

Furniss, T. (1993). Abuso Sexual da Criança: uma abordagem multidisciplinar. Porto Alegre: Artes Médicas.

Giordani, J. P., Seffner, F. \& Dell'aglio, D. D. (2017). Violência escolar: percepções de alunos e professores de uma escola pública. Psicol. Esc. Educ., Maringá, 21 (1), p. 103-111. 
Giusti, J. S. (2013). Automutilação: características clínicas e comparação com pacientes com transtorno obsessivo-compulsivo. Tese (Doutorado em Ciências). Faculdade de Medicina da Universidade de São Paulo, Universidade de São Paulo, São Paulo. <www.teses.usp.br/teses/disponiveis/5/5142/tde-03102013113540/pt-br.php>.

Hawton K, Saunders K E, O'Connor R C. (2012) Self-harm and suicide in adolescents. Lancet. 23; 379 (9834):2373-82. doi: 10.1016/S0140-6736(12)603225. PMID: 22726518.

Leong C H, Wu A M, Poon M M. (2014) Measurement of perceived functions of non-suicidal self-injury for Chinese adolescents. Arch Suicide Res. 18 (2): 193-212. doi: 10.1080/13811118.2013.824828. PMID: 24568552.

Lopes Neto \& Aramis, A. (2005) Bullying: comportamento agressivo entre estudantes. Jornal de Pediatria [online]. 2005 , v. 81 , n. 5 suppl, pp. s164-s172. https://doi.org/10.1590/S0021-75572005000700006. ISSN 1678-4782. https://doi.org/10.1590/S0021-75572005000700006.

Macedo, M. M. K., Baldo, M.A., Santos, R. L., Ribas, R. F., Silva, S. M. \& Gonçalves, T. G. (2011) Motivos de busca de atendimento psicológico por adolescentes em uma clínica-escola. Psicol. teor.prat., São Paulo, v. 13, n. 2, p. 63-75. http://pepsic.bvsalud.org/scielo.php?script=sci_arttext\&pid=S1516$36872011000200005 \& \operatorname{lng}=$ pt\&nrm=isso.

Macedo, V. C. D. \& Monteiro, A. R. M.. (2006). Educação e saúde mental na família: experiência com grupos vivenciais. Texto contexto enferm., Florianópolis, 15 (2), p. 222-230. /www.scielo.br/scielo.php?script=sci_arttext\&pid=S0104- 07072006000200005\&lng=en\&nrm=iso

Magnani, R. M.\& Staudt, A. C. P. (2018). Estilos parentais e suicídio na adolescência: uma reflexão acerca dos fatores de proteção. Pensando fam., Porto Alegre, 22 (1), p. 75-86. <http://pepsic.bvsalud.org/scielo.php?script=sci_arttext\&pid=S1679-494X2018000100007\&lng=pt\&nrm=iso>.

Martins, G. A. (2008) Estudo de caso: uma reflexão sobre a aplicabilidade em pesquisas no Brasil. Revista de Contabilidade e Organizações, v. 2, n. 2, p. 9-18, jan./abr.

Mângia, E. F.; Assumpção, C. N.; Quinta, J. M. \& Rufino, M. de F. (2003) Necessidades de adolescentes com sofrimento psíquico. Revista de Terapia Ocupacional da Universidade de São Paulo, [S. l.], v. 14, n. 3, p. 123-132. DOI: 10.11606/issn.2238-6149.v14i3p123-132. Disponível em: https://www.revistas.usp.br/rto/article/view/13927.

Meirinhos, M.; Osório, A. (2016). O estudo de caso como estratégia de investigação em educação. Eduser - Revista de Educação, [S.1.], v. 2, n. 2. ISSN 16454774. <https://www.eduser.ipb.pt/index.php/eduser/article/view/24>. doi: http://dx.doi.org/10.34620/eduser.v2i2.24.

Monteiro, A. R. M; Teixeira, L. A.; Silva, R. S. M; Rabelo, K. P. S; Tavares, S. F. V \& Távora, R .C. O. (2012). Sofrimento psíquico em crianças e adolescentes: a busca pelo tratamento. Escola Anna Nery [online], v. 16, n. 3, pp. 523-529. <https://doi.org/10.1590/S1414-81452012000300014>. Epub 12 Set 2012. ISSN 2177-9465. https://doi.org/10.1590/S1414-81452012000300014.

Pasini, A. L. W.; Silveira, F. L. da; Silveira, G. B. da; Busatto, J. H.; Pinheiro, J. M.; Leal, T. G.; Laguna, T. F. dos S.; Jaeger, F. P.; Guazina, F. M. N. \& Carlesso, J. P. P. (2021) Suicide anddepression in adolescence: riskfactorsandpreventionstrategies. Research, Society and Development, [S. l.], v. 9, n. 4, p. e36942767, 2020. DOI: 10.33448/rsd-v9i4.2767. Disponível em: https://rsdjournal.org/index.php/rsd/article/view/2767.

Pereira, M. (2000) Epidemiologia: teoria e prática. Rio de Janeiro: Editora Guanabara/Koogan S.A.

Pereira, A. S. P.; Shitsuka, D. M.; Parreira, F. J. \& Shitsuka, R. (2018). Metodologia da pesquisa científica [recurso eletrônico] 1. ed. Santa Maria, RS : UFSM, NTE. e-book

Picanço, A. L. B. (2012). A Relação entre escola e família - As suas implicações no processo de ensino-aprendizagem. Escola Superior de Educação João de Deus. Dissertação. Mestrado em Ciências da Educação - Supervisão Pedagógica. Lisboa.

Pigozi, P L M, Ana Lúcia. (2015). Bullying na adolescência: visão panorâmica no Brasil. Ciência \& Saúde Coletiva [online]. 20 (11), pp. 3509-3522. <https://doi.org/10.1590/1413-812320152011.05292014>.

Pinto, A. C. S., Luna, I.Z., Sivla, A.A., Costa, P.N., Batista, V.A., Braga, A.B. \& Souza, M.A. (2014) Fatores de risco associados a problemas de saúde mental em adolescentes: revisão integrativa. Rev. esc. enferm. USP [online]. v.48, n.3, p.555-564.

Prado, M. C. C. A. (Org.). (2004). O mosaico da violência. São Paulo: Vetor.

Pratta, E. M. M.; Santos, M. A. (2006). Reflexões sobre as relações entre drogadição, adolescência e família: um estudo bibliográfico. Estud. Psicol. , Natal, 11 (3), p. 315-322. http://www.scielo.br/scielo.php?script=sci_arttext\&pid=S1413-294X2006000300009\&lng=en\&nrm=iso

Prieto, D. Y. C. (2017). Precisamos falar sobre suicídio. FEBRAPSI. Mesa Redonda, Brasília: DF.

Ribeiro, K. C. S., Medeiros, C. S., Coutinho, M. P. L. \& Carolino, Z. C. G (2012). Representações sociais e sofrimento psíquico de adolescentes com sintomatologia depressiva. Psicol. teor. prat., São Paulo , v. 14, n. 3, p. 18-33. <http://pepsic.bvsalud.org/scielo.php?script=sci_arttext\&pid=S1516$36872012000300002 \& \operatorname{lng}=$ pt\&nrm=iso $>$.

Romaro, R. A; Capitão, C. G. (2007). As faces da violência: aproximações, pesquisas, reflexões. São Paulo: Vetor.

Romanelli, G. (2003). Autoridade e poder na família. In: Carvalho, M.C.B. (Org.). A família contemporânea em debate. São Paulo. Cortez, p.73-88.

Rossi, L. M., Marcolino, T. Q., Speranza, M. \& Cid, F. B. (2019) Crise e saúde mental na adolescência: a história sob a ótica de quem vive. Cadernos de Saúde Pública [online]. 2019, v. 35, n. 3. <https://doi.org/10.1590/0102-311X00125018>. Epub 11 Mar 2019. ISSN 1678-4464. https://doi.org/10.1590/0102$311 \mathrm{X} 00125018$.

Schilling, F. (2014). A sociedade da insegurança e a violência na escola. São Paulo: Summus. 
Research, Society and Development, v. 10, n. 10, e437101018929, 2021

(CC BY 4.0) | ISSN 2525-3409 | DOI: http://dx.doi.org/10.33448/rsd-v10i10.18929

Senna, S. R. C. M., \& Dessen, M. A. (2012). Contribuições das teorias do desenvolvimento humano para a concepção contemporânea da adolescência. Psicologia: Teoria e Pesquisa,1, 101-108.

Serpa Jr., O., Campos, R.O.C., Pitta, A.M., Diaz, A.G. \& Dahl, E.L. (2014). Experiência narrativa e conhecimento: a perspectiva do psiquiatra e do usuário. Physis Revista de Saúde Coletiva. Rio de Janeiro, 24 (4), 1053-1077.

Soares, G. G. (2020). Sofrimento psíquico e adolescência: reflexões acerca dos sentidos atribuídos à adolescência. Boletim de Conjuntura (BOCA), Boa Vista, v. 4, n. 10, p. 100-107, oct. 2020. ISSN 2675-1488. <https://revista.ufrr.br/boca/article/view/Soares>. doi:http://dx.doi.org/10.5281/zenodo.4073586.

Volling B L\&, Elins J L. (1998). Family relationships and children's emotional adjustment as correlates of maternal and paternal differential treatment: a replication with toddler and preschool siblings. Child Dev. 69 (6): 1640-56. PMID: 9914644.

Vicentin M C G \& Gramkow G. (2010). Que desafios os adolescentes autores de ato infracional colocam ao SUS? Algumas notas para pensar as relações entre saúde mental, justiça e juventude. In: Lauridsen-Ribeiro E, Tanaka OY, organizadores. Atenção em saúde mental para crianças e adolescentes no SUS. São Paulo: Editora Hucitec, p. 337-51

World Health Organization. (2016). Practice Manual for Establishing and Maintaining Surveillance Systems for Suicide Attempts and Self-Harm; World Health Organization: Geneva, Switzerland. 